\title{
Rotavirus Diarrhoea among Children under Five Years in a Tertiary Level Government of Rajasthan
}

\author{
Ari $\mathbf{A}^{1}$, Chaudhary $\mathbf{R}^{2}$, Sharma $\mathbf{S D}^{3}$
}

${ }^{1}$ Dr. Abhijit Ari, MBBS, MD. ${ }^{2}$ Dr. Ruchi Chaudhary, MBBS, MD. ${ }^{3} \mathrm{Dr}$. SD Sharma, MBBS, MD.All from the Department of Paediatrics, S.M.S Medical College, Jaipur, Rajasthan

\section{Address for correspondence:}

Abhijit Ari,

Jayram Reddy Building, Kithganhalli,

Narayana Hrudayalaya,

Bangalore, India

Tel: +918013255818, +917022620969

E-mail:abhijitari@gmail.com

Acknowledgements: The authors acknowledge all the children and their parents who participated in this study.

Funding: Nil

Conflict of Interest: None

Permission from IRB: Yes

Ethical dilemmas faced during study: No

\section{How to cite}

Ari A, Chaudhary R, Sharma SD. Rotavirus Diarrhoea among Children under Five Years in a Tertiary Level Government of Rajasthan. J Nepal Paediatr Soc 2016;36(3):273-276.

doi: http://dx.doi.org/10.3126/jnps.v36i3.15398

This work is licensed under a Creative Commons Attribution 3.0 License.

\section{(c) (i)}

\begin{abstract}
Introduction: Rotavirus is the leading cause of severe, dehydrating diarrhoea in young children globally.Studies indicate that rotavirus causes approximately 40 percent of childhood diarrhoea hospitalization worldwideand around 39 percent in India in lessthan 5 years of age.This study aimed to estimate the prevalence of rotavirus diarrhea among hospitalized children aged under five years.Materials and Method: Stool samples were collected from children who fall within the age range of 0-5 years with acute diarrhea and samples are tested for rotavirus by the enzyme linked immunosorbent assay (ELISA). Result: Out of 349 samples, 104(29.8\%) cases were positive for rotavirus by ELISA. Therefore the prevalence of rotavirus infection among hospitalized patient under this study was $29.8 \%$.Conclusion: Rotavirus is an important cause of diarrhea in hospitalized children.
\end{abstract}

Key words: Diarrhea, enzyme-linked immunosorbent assay (ELISA), rotavirus, Rajasthan

\section{Introduction}

$\mathrm{R}$ otaviruses are the most common cause of severe infant and childhood gastroenteritis worldwide, responsible for an estimated 23 million outpatient visits, 2.3 million hospitalizations, and over half a million deaths annually among children under five years of age ${ }^{1,2}$. Each year an estimated 527,000 children die from rotavirus diarrhoea ${ }^{3,4,5}$. It's account for approximately one in six deaths among children younger than five years ${ }^{3,4,5}$.The majority of these deaths occur in developing countries ${ }^{2,6}$. Rotavirus causes about $30-50 \%$ of diarrheal diseases in young children and the prevalence of severe rotavirus disease has remained high ${ }^{7,8}$. Very few studies on the prevalence of rotavirus among children have been conducted in Rajasthan.This study aimed to identify the proportion of children with acute gastroenteritis infected with rotavirus through systematic sampling over a one year period in a tertiary care Government hospital in Rajasthan.

\section{Materials and Methods}

This study was conducted at a Government tertiary care hospital in Jaipur, Rajasthan, India from October 2011 to September 2012. 
This study included all hospitalized children of aged under 5 years who had presented with acute watery diarrhea. Informed consent was obtained for each child from the respective parent/guardian after explaining the purpose of the study. A case of diarrhea was defined as increased stool frequency, compared with the usual pattern occurring in a child aged under five years for whom the parents sought care for treatment of diarrhea ${ }^{9}$. Clinical details including age, sex, duration of illness, number of stools, associated vomiting and fever, degree of dehydration, and concomitant illness we rerecorded on a standardized reporting form. Detailed examination was done, dehydration was classified and treated as per WHO protocol and severity of illness was classified as per Vesikari scoring system for diarrheal illness ${ }^{10}$.Stool specimens from all hospitalized children aged under five years who had presented with acute watery diarrhea were collected and stored in the refrigerator at $4^{\circ} \mathrm{C}$ and later transported to the laboratory of our hospital at $4^{\circ} \mathrm{C}$. Samples were tested for the presence of rotavirus using a commercially available antigen detection apparatus, the enzyme-linked immunosorbent assay (ELISA) (Premier ${ }^{\mathrm{TM}}$ Rotaclone $^{\circledR}$, Meridian Biosciences, Cincinnati, Ohio, USA), as per kit protocol. Samples showing an optical density value of $\geq 0.150$ were reported as positive. Enzyme immunoassay has a sensitivity of $96 \%, 99 \%$ specificity, $98 \%$ of positive predictive value and $98 \%$ of negative predictive value ${ }^{11}$. Statistical analysis were performed using SPSS (Statistical Package for Social Sciences) software (SPSS version 20; SPSS Inc, Chicago, IL). Chi square test was applied. $p<0.05$ was considered statistically significant.

\section{Result}

For the one year period, a total of 349 children were included in the study group. Among the study subjects, a majority of them were male children [247 (70.7\%)], and $102(29.2 \%)$ were female children. The stool samples of $104(29.8 \%)$ children were positive for rotavirus by ELISA [Table 1].

Among 349 cases, a majority [246 (70.4\%)] were in the age group of $<15$ months. Similarly, out of 104 ELISA-positive cases, $83(79.8 \%)$ were found to be in the same age group.There were 5 rotavirusinfected cases among neonates and in the initial 2 months of age [Table 2].Applying chi-square analysis, it was found that there was strong statistical significant difference $(p-0.007)$ in ELISA reactivity between different age groups of cases.

Rotaviral diarrhea was more common during winter months i.e. November to February. $61.5 \%$, with highest prevalence in the month of February (22.1\%).Lower prevalence $28.8 \%$ during summer and monsoon months i.e. March- September (Figure 1).

Severity of rotavirus diarrhoea was shown in Table 3as per Vesikari scoring. It was seen that severity of illness is more $(p=0.003)$ in rotavirus positive diarrhoeal cases.

Table 1: Distribution of Rotavirus cases according to sex

\begin{tabular}{cccc}
\hline \multirow{2}{*}{ Sex } & \multicolumn{3}{c}{ Rotavirus status $(\mathbf{n = 3 4 9 )}$} \\
\cline { 2 - 4 } & Positive & Negative & Total \\
\hline Male & $75(72.1 \%)$ & $172(70.2 \%)$ & 247 \\
\hline Female & $29(27.9 \%)$ & $73(29.8 \%)$ & 102 \\
\hline
\end{tabular}

Table 2: Distribution of Rotavirus cases according to age group

\begin{tabular}{cccc}
\hline \multirow{2}{*}{$\begin{array}{c}\text { Age group of children } \\
\text { (months) }\end{array}$} & \multicolumn{2}{c}{ Rotavirus status of children } & \multirow{2}{*}{ Total } \\
\cline { 2 - 4 } & Positive & Negative & 28 \\
\hline $0-2$ & $5(4.8 \%)$ & $23(9.3 \%)$ & 58 \\
\hline $3-5$ & $14(13.4 \%)$ & $44(17.9 \%)$ & 62 \\
\hline $6-8$ & $17(16.3 \%)$ & $45(18.3 \%)$ & 56 \\
\hline $12-14$ & $30(28.8 \%)$ & $26(10.6 \%)$ & 42 \\
\hline $15-17$ & $17(16.3 \%)$ & $25(10.2 \%)$ & 12 \\
\hline $18-23$ & $4(3.8 \%)$ & $8(3.2 \%)$ & 23 \\
\hline $24-35$ & $7(6.7 \%)$ & $16(6.5 \%)$ & 27 \\
\hline $36-48$ & $5(4.8 \%)$ & $22(8.9 \%)$ & 23 \\
\hline $49-59$ & $4(3.8 \%)$ & $19(7.7 \%)$ & 18 \\
\hline
\end{tabular}




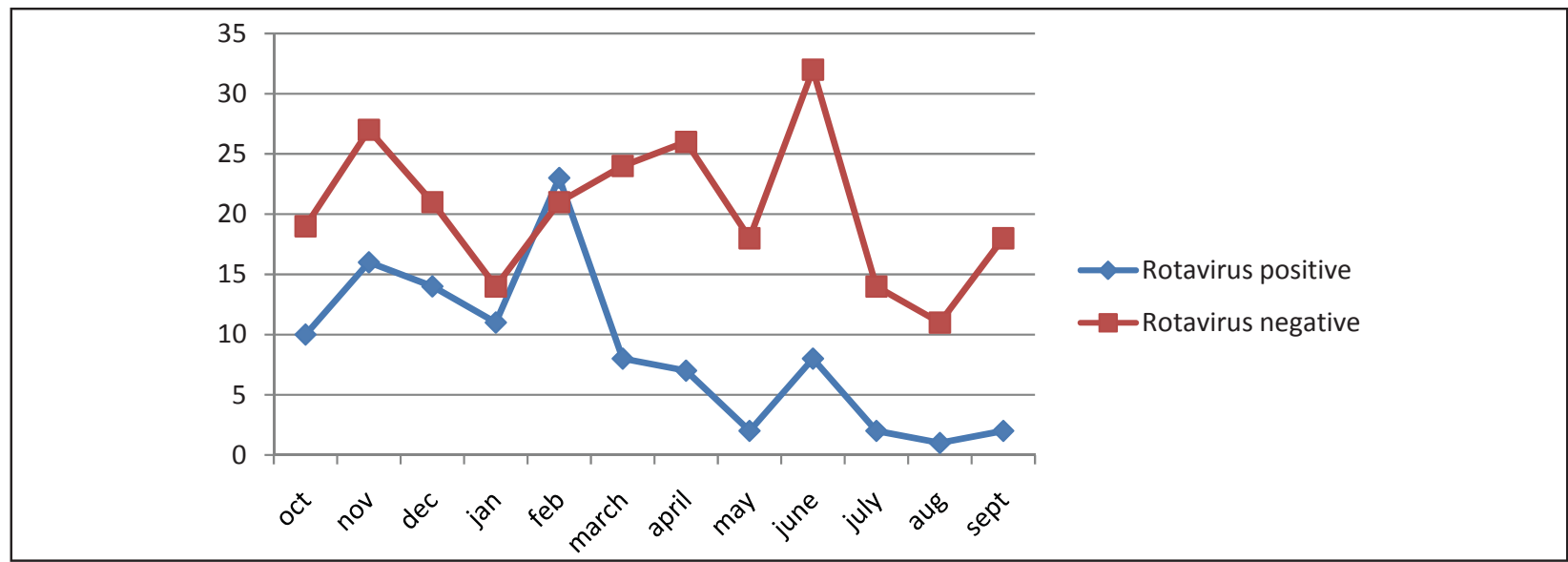

Fig 1: Seasonal distribution of rotavirus cases

\section{Discussion}

In the present study, it was found that $29.8 \%$ of the children aged less than five years, hospitalized with the complaint of diarrhea are due to rotavirus which correlates very well studies conducted in India.Bahl et al ${ }^{12}$ reported $23.5 \%$ positivity, Banerjee et $a^{13}$ reported $27.4 \%$ positivity, and Ramani and $\mathrm{Kang}^{14}$ reported $20-35 \%$ positivity. Comparatively, lower prevalence rates of rotavirus diarrhea had been reported in India from Bangalore $(16.3 \%)^{15}$, Calcutta $(14.6 \%)^{16}$, and Chandigarh $(15.9 \%)^{17}$; because they useddifferent method of detection (latex slideagglutination test which is less sensitive to ELISA) ofrotavirus antigen from stool, as well as because ofdifference in climate and socio demographic status.

In this study, maximum Rotavirus positivity was found in the age group of $9-11$ months $(28.8 \%$ $p$-value<0.05) (Table 2), which correlates well withnumerous studies conducted in India. Dutta et $\mathrm{al}^{18}$ revealed that rotavirus was most frequently detectedin the age group of $6-11$ months (26.6\%), and wasnot detected at all above 24 months of age. Nath et al $^{19}$ demonstrated that the overall prevalence of rotavirus diarrhea was significantly higher in childrenbelow 2 year as compared to those between 2-5 yearsof age. Phukan et $\mathrm{al}^{20}$ showed rotavirus diarrhea was significantly high in children between 11 to 20 months (37.75\%).

As per Vesikari clinical scoring system, severity of diarrhoea was classified as mild, moderate, severe and

\section{References}

1. Parashar UD, Burton A, Lanata C, Boschi-Pinto C, Shibuya K, Steele D, et al. Global mortality associated very severe. As per this system, severity of rotavirus diarrhoea was more in positive cases and it is statistically significant $(p<0.005)$. Similar findings are also observed in other studies ${ }^{13,26}$.

Regarding seasonality, some studies in India have found no association between rotavirus infection and the time of year ${ }^{13,21}$. Other studies have observed an increase in rotavirus-associated diarrhea during the winter months, October-February, throughout the country ${ }^{12,22,23}$. Rotavirus was markedly seasonal in northern India but was less seasonal in southern locations with a more tropical climate $20,24,25$. Our study also shows prevalence of rotavirus diarrhoea is maximum during winter months.

\section{Conclusion}

This study has made it clear that one-fourth of the diarrheal disorders among children aged less than five years are due to rotavirus, which calls for stringent preventive measures in terms of vaccination against rotavirus and it is more prevalent during winter months of the year.

The strengths of this study include use of the WHO protocol for diagnosis and management of diarrhea, laboratory confirmation of Rotavirus and severity is classified as per Vesikari scoring system. There were a few limitations of present study. As this study is hospitalbased, the prevalence of rotavirus might have been different from the actual prevalence in the community. The incidence of the disease could not be calculated in this study.

with rotavirus disease among children in 2004. J Infect Dis 2009;200:9-15

2. Parashar UD, Hummelman EG, Bresee JS, Miller MA, Glass RI. Global illness and deaths caused by rotavirus disease in children. Emerg Infect Dis 2003;9:565-72; 
3. Shaun, K., Morris, ShallyAwasthi, Ajay Khera, Diego, G., Bassani, Gagandeep, Kang, Umesh, D., Parashar, et al. 2012. Bulletin of the World Health Organization; 90:720727.doi:10.2471/BLT.12.101873. Availablefrom:http://www.who.int/bulletin/ volumes/90/10/12-101873/en/.

4. Payne DC, Wikswo M, Parashar UD. VPD surveillance manual.5th edn. 2011 Rotavirus: Chapter 13-1 - http:// www.cdc.gov/vaccines/pubs/surv-manual/ chpt13rotavirus.pdf

5. Kargar M, Najafi A, Zandi K, Hashemizadeh Z. Genotypic distribution of rotavirus strains causing severe gastroenteritis in children under 5 years old in Borazjan, Iran. Afr J Microbiol Res 2011;5(19):2936-41.

6. World Health Organization. Estimated rotavirus deaths for children under 5 years ofage,2004.http://www. who.int/immunization_monitoring/burden/rotavirus_ estimates/en/

7. Mwenda JM, Ntoto KM, Abebe A, Enweronu-Laryea C, Amina I, Mchomvu J, Kisakye A, Mpabalwani EM, Pazvakavambwa I, Armah GE, Seheri LM, Kiulia NM, Page N, Widdowson MA, Steele AD. Burden and epidemiology of rotavirus diarrhea in selected African countries: preliminary results from the African Rotavirus Surveillance Network. J Infect Dis2010;202 Suppl: S5S11.

8. Bernstein DI. Rotavirus overview.Pediatr Infect Dis J2009;28(3Suppl):S50-3

9. Diarrhoea Treatment Guidelines (including new recommendations for the use of ORS and zinc supplementation) for ClinicBased Healthcare Workers. MOST, WHO, UNICEF , IZiNCG. 2005 (http://www.who. int/child-adolescenthealth/Emergencies/Diarrhoea_ guidelines.pdf).

10. Ruuska T, Vesikari T, Rotavirus disease in Finnish children: Use of numerical scores for clinical severity of diarrhoeal episodes. Scand J Infect Dis 1990;22:25967.

11. Buser J, Risch L, Rutz T, Manang S, Munzinger J.Comparison of a rotavirus latex agglutination test with two rapid immunochromatographic test devices for detection of rotavirus in human feces.Eur J Clin Microbiol Infect Dis 2001;20(4):295-96.

12. Bahl R, Ray $P$, Subodh $S$, Shambharkar $P$, Saxena et al. Incidence of severe rotavirus diarrhea in New Delhi, India, and $G$ and $P$ types of the infecting rotavirus strains. J Infect Dis2005;1(192):114-19.

13. Indrani Banerjee, Sasirekha Ramani, Beryl Primrose, Prabhakar Moses, Miren IturrizaGomara, James J. Gray et al. Comparative study of the epidemiology of rotavirus in children from a community-based birth cohort and a hospital in South India. J Clin Microbiol 2006;44(7):2468-74.
14. Ramani S, Kang G. Burden of disease \& molecular epidemiology of group A rotavirus infections in India. Indian J Med Res 2007;125:619-32

15. Bhat $P$, Macaden $R$, Unnykrishnnan $P$, Rao HG. Rotavirus and bacterial enteropathogens in acute diarrhoea of young children in Bangalore. Ind $\mathrm{J}$ Med Res 1985;82:105-9.

16. Sen D, Saha MR, Balakrish Nair, Das P, Niyogi S, Bhattacharya SK, et al. Etiological spectrum of acute diarrhoea in hospitalized patients in Calcutta. Ind J Med Res 1985;82:286-91.

17. Singh PB, Sreenivasan MA, Pavri KM. Viruses in acute gastroenteritis in children in Pune, India. Epidem Infect 1989;102:345-53.

18. Dutta SR, Khalfan SA, Baig BH, Philipose L, Fulay Fil $R$. Epidemiology of rotavirus diarrhoea in children under five years in Bahrain. Int J Epidemiol 1990;19:722-27.

19. Nath G, Singh SP, Sanyal SC. Childhood diarrhoea due to rotavirus in a community. Indian $J$ Med Res1992;95(4):259-62.

20. Phukan AC, Patgiri DK, Mahanta J. Rotavirus associated acute diarrhoea in hospitalized children in Dibrugarh, north-east India. Indian J Pathol Microbiol 2003;46:274-78.

21. Mukherjee A, ChaĴopadhyay S, Bagchi P, DuĴa D, Singh NB, Arora R, et al. Surveillance and molecular characterization of rotavirus strains circulating in Manipur, north-eastern India: Increasing prevalence of emerging G12 strains. Infect Genet Evol 2010;10:31120.

22. Kahn G, Fitzwater S, Tate J, Kang G, Ganguly N, Nair $\mathrm{G}$, et al. Epidemiology and Prospects for Prevention of Rotavirus Disease in India. Indian Pediatr2012;49:469.

23. Saravanan P, Ananthan S, Ananthasubramanian M. Rotavirus infection among infants and young children in Chennai, South India. Indian J Med Microbiol 2004;22:212-21

24. Kang G, Arora R, Chitambar SD, Deshpande J, Gupte MD, Kulkarni M, et al.; Indian Rotavirus Strain Surveillance Network. Multicenter, hospitalbased surveillance of rotavirus disease and strains among Indian children aged $<5$ years. J Infect Dis2009;200:S147-53.

25. Ray P, Sharma S, Agarwal RK, Longmei K, Gentsch JR, Paul VK, et al. First detection of $\mathrm{G} 12$ rotaviruses in newborns with neonatal rotavirus infection at All India Institute of Medical Sciences, New Delhi, India. J Clin Microbiol 2007;45:3824-27.

26. Johannes Forster, Alfredo Guarino , Nathalie Parez et al Hospital-Based Surveillance to Estimate the Burden of Rotavirus Gastroenteritis Among European Children Younger Than 5 Years of Age. Pediatrics 2009;123(3);e393-e400. 